\title{
Belleza, sentido y creación en la enseñanza de la Lengua
}

\section{Beauty, Meaning and Creation in the Teaching of Language}

\author{
Bruno Rosario Candelier \\ Director de la Academia Dominicana de la Lengua \\ Santo Domingo, República Dominicana \\ acadom2003@hotmail.com
}

Fecha de recepción: 20 de junio de 2017

Fecha de aceptación: 15 de julio 2017

Favor de citar este artículo de la siguiente forma:

Rosario Candelier, B. (2017). Belleza, sentido y creación en la enseñanza de las letras

Revista AULA. Vol. 61, Número 1, julio-diciembre 2017. Santo Domingo: Amigos del Hogar

\section{RESUMEN}

Este trabajo muestra cómo la belleza y el sentido en el proceso de la enseñanza de la Lengua impulsan al estudiante al dominio de la misma. Al darse cuenta del rol que juega la palabra en la vida de la conciencia, entiende su importancia y aprecia el canto maravilloso del ser que se expresa desde las profundidades de la dimensión espiritual. La belleza es generalmente una fuente de contemplación, motivación e inspiración; el profesor debe concitarla para despertar la conexión con el alma de lo viviente. Es fuente creativa de exaltación y de valoración para todo lo que, de alguna manera, enaltece la sensibilidad y la conciencia porque no solo hemos de cultivar la sensibilidad sino también la conciencia. Una conciencia de las cosas que nos rodean; una conciencia del impacto que las cosas ejercen en nuestra sensibilidad; y una conciencia de que entramos en comunión con las cosas y, por ese vínculo, establecemos un punto de contacto con la realidad material y la realidad inmaterial. Ese contacto suele ser exclusivo, inspirador y sugerente. Dado lo anterior, la belleza tiene una vertiente que de alguna manera sirve para que nos asombremos ante el encanto del mundo y el esplendor de la Creación.

Palabras clave: Belleza, conciencia, creación, dimensión espiritual, Lengua, sentido

\section{ABSTRACT}

This paper shows how beauty and meaning in the process of teaching the Language impels the student to its domain. When he realizes the role that words play in the life of the conscience he understands its importance and appreciates the wonderful song that is expressed from the depths of the spiritual dimension. Beauty is generally a source of contemplation, motivation and inspiration. And the teacher must awaken the connection with the soul of everything that exist. It is a creative source of exaltation and appreciation for all that in some way enhances the sensitivity and the conscience, because we are not only to cultivate the sensibility, but also the conscience. An awareness of the things around us; an awareness of the impact that things exert on our sensibility; and an awareness that we enter into communion with things and, through that bond, establish a point of contact with the material reality and the immaterial reality, and that contact is usually exclusive, inspiring and suggestive. Given the above, beauty has a slope that somehow serves to amaze us with the charm of the world and the splendor of creation.

Keywords: Beauty, consciousness, creation, spiritual dimension, language, meaning. 


\section{Belleza, sentido y creación en la enseñanza de la Lengua Beauty, meaning and creation in the teaching of language}

La belleza y el sentido juegan un rol esencial en la vida interior de la conciencia. La dimensión sensorial de lo viviente, con sus manifestaciones hermosas, inspiran el sentimiento de la belleza, dimensión que cautiva la sensibilidad y atiza la conciencia. Naturalmente la percepción de la belleza es la vertiente primordial en nuestra percepción de las cosas que nos estimulan sensorialmente e inyectan en la sensibilidad un influjo emocional y espiritual. Somos sensibles a la belleza y a todos nos apela el sentido para comprender la esencia de fenómenos y cosas.

Cuando laboré como profesor de Lengua Española en la Escuela Normal "Teodoro Henneken", de Licey al Medio en Santiago, seleccioné a los estudiantes que daban notaciones de una vocación literaria, y en ese plantel escolar formé en 1967 un grupo literario con el nombre de "Littera", que fue el primer taller literario creado en la República Dominicana. Allí se formó el poeta, novelista y académico de la lengua José Enrique García, que llegó a ser profesor de la Universidad Nacional Pedro Henríquez Ureña. Entonces, como ahora, el autor de esta afirmación valoraba la belleza y el sentido en el cauce de la palabra que alienta la creación, palabra que motivaba a los estudiantes y contribuía al desarrollo de la sensibilidad espiritual y estética.

Lo más importante en la enseñanza de cualquier disciplina es la motivación que sembremos en nuestros estudiantes. Ya decía Plutarco (s.f), el antiguo educador y filósofo griego, que los cerebros (almas) no son vasos que se han de llenar, sino antorchas que se han de encender. Si logramos despertar la conciencia por la lengua en nuestros estudiantes, ellos mismos procurarán la vía para lograr los conocimientos léxicos, gramaticales y ortográficos hasta obtener plena competencia en las artes del lenguaje, que son hablar, leer, comprender y escribir.

Ahora bien, lo importante de la belleza y el sentido es la actitud que podemos asumir ante esas manifestaciones de las cosas. Por ejemplo, desde la antigüedad se ha enseñado que debemos tener una apreciación sensorial de la belleza para valorarla en sí misma. Esta genera en nuestra sensibilidad lo que los teóricos llaman "emoción estética", que es la reacción afectiva que el encanto de las cosas concita en nuestra sensibilidad. Pero además de la emoción estética que puede ser superficial o profunda-, la belleza tiene una dimensión más honda, y es precisamente la valoración del sentido profundo que despierta. Ante esa dimensión podríamos hablar de una actitud de valoración cósmica hacia la belleza, viéndola como una fuente de verdad e incluso de ideales, de tal manera que nos lleva a la verdad, porque hay una verdad de la belleza, como también la verdad del pensamiento que la expresa. El pensamiento genera conceptos, juicios y verdades. La contemplación de las cosas inspira intuiciones y vivencias, así como sensaciones y conceptos.

Hemos de enseñar que nuestros pensamientos se manifiestan en imágenes y conceptos, y que pensar en imágenes o pensar en conceptos va a pautar la diferencia entre el pensar y el artista. El pensador reflexiona ante las cosas y, en tal virtud, hace filosofía, ciencia, ensayos. El artista se emociona ante las cosas y, en tal virtud, escribe poesía, compone creaciones pictóricas, arquitectónicas o musicales, lo que indica que existe una belleza del pensamiento y una belleza de la forma.

Las personas que tienen una sensibilidad especial, es decir, una disposición para percibir 
la dimensión profunda y trascendente de las cosas, pueden apreciar la dimensión metafísica y mística de la belleza y percibirla como expresión de lo divino. Sócrates en los Diálogos de Platón (Platón, 1970, original s.f) declaró que lo divino, es lo bello, lo bueno y lo sabio y todo lo que posee análogas cualidades. Ahí es donde los poetas canalizan su disposición creadora, sobre todo los creadores de poesía mística.

La belleza es generalmente una fuente de contemplación, motivación e inspiración. Y el profesor debe concitarla para despertar la conexión con el alma de lo viviente. Es fuente creativa de exaltación y de valoración para todo lo que de alguna manera enaltece la sensibilidad y la conciencia, porque no solo hemos de cultivar la sensibilidad, sino también la conciencia. Una conciencia de las cosas que nos rodean; una conciencia del impacto que ellas ejercen en nuestra sensibilidad; una conciencia de que entramos en comunión con las cosas y, por ese vínculo, establecemos un punto de contacto con la realidad material y la realidad inmaterial. Ese contacto suele ser exclusivo, inspirador y sugerente. Dado lo anterior, la belleza tiene una vertiente que de alguna manera sirve para que nos asombremos ante el encanto del mundo y el esplendor de la creación.

Es importante subrayar el hecho de que nosotros, como seres establecidos en una sociedad -con una historia, una lengua y una culturatambién estamos instalados en el mundo. Desde nuestra sensibilidad establecemos un punto de contacto con la naturaleza de lo viviente, y la belleza es la primera señal que nos da cuenta de lo que nos rodea; el encanto de las cosas, sus datos sensoriales -colores, olores, sabores, sonidos, formas y texturas-. Se trata de las manifestaciones externas, sensibles y suprasensibles, de lo real. Hemos de inculcar en nuestros alumnos que, además de la realidad material, existe una realidad imaginaria y una realidad trascendente, a las que se suma la realidad virtual y la realidad ideal. Esto despierta un interés genuino para el desarrollo de nuestra condición pensante y nuestra inclinación contemplativa, porque al tiempo que somos seres contemplativos, somos también seres pensantes, y eso enriquece una parte importante de nuestra vida: la dimensión interior $\mathrm{y}$, de un modo especial, la vida interior de la conciencia.

El hecho de crear belleza es un factor importante que nos distingue, no solo entre los seres humanos sino entre todas las criaturas de la creación. En virtud del Logos de la conciencia hemos desarrollado la capacidad para reflexionar, con la capacidad para hablar, intuir y crear. Esto es lo que nos diferencia de los animales y las plantas. Creamos belleza porque tenemos inclinación estética. Creamos conceptos a los que podemos incluso instaurar un sentido lúdico, de diversión y de fascinación. Todo eso es hermoso y fuente de creatividad, que el profesor de lengua española debe ponderar en su docencia para hacer de la palabra la dotación que nos enaltece en razón de lo que podemos crear con ese alto poder de nuestra conciencia.

Estas consideraciones se prestan para hacer reflexiones profundas en torno a la vida, la naturaleza, la creación, el impacto y el valor que tiene cada ser humano como sujeto pensante y sintiente ante la totalidad de lo viviente. Nosotros formamos parte de la realidad universal y, al formar parte de la Totalidad -si tomamos conciencia de esa realidad-, apreciamos lo que somos en el concierto de la creación, gracias a la valoración de la belleza y el sentido del mundo. Como un singular don de la condición humana y de la energía interior de la conciencia, la lengua encarna el caudal de palabras que nos sirven para el conocimiento del mundo y hacen posible la percepción de lo real, el testimonio de nuestra reflexión y el poder de nuestra creatividad. 
El profesor de Lengua y de Literatura ha de tener presente que la palabra tiene dos aspectos claramente definibles y diferenciables en su misma concreción verbal: la textura de la forma y el sentido del concepto. Ambos aspectos se vinculan en el arte literario: el primer aspecto se canaliza en el estilo; el segundo aspecto se relaciona con la conceptuación del pensamiento que, en la obra literaria, tiene la función de apelación, cosmovisión y orientación.

La poesía es la vía intuitiva, estética y creativa para conocer el sentido profundo de la realidad. En tal virtud, la poesía propicia una luminosa comprensión de lo viviente, ya que su función radica en ser la voz de la conciencia, canalizar la voz de las cosas y atrapar la voz superior de la realidad trascendente. Además de la belleza de la forma, la creación poética ejerce un influjo de honda repercusión cognitiva, afectiva y espiritual, ya que revela la voz interior, la voz subjetiva y la voz universal de fenómenos y cosas. La voz interior es la voz individual, personal y entrañable, de cada sujeto hablante; la voz subjetiva es el susurro, el sentido que las cosas proyectan; y la voz universal alude a los efluvios sobrenaturales que las irradiaciones cósmicas proyectan en fenómenos específicos mediante señales, voces, imágenes, destellos o estelas de la trascendencia.

Por esa razón, al hablar de la belleza en la palabra, se puede enfocar el asunto desde tres perspectivas diferentes: Primero, desde la belleza del concepto o el primor del pensamiento, que se funda en el sentido de las cosas, dimensión que entraña una manera de percibir y expresar lo que apunta la belleza profunda. En este sentido se manifiesta la voz interior, como enunciación de la intuición profunda, $\mathrm{y}$ la voz universal, como testimonio de las verdades reveladas. Asimismo, la capacidad de reflexión sobre el sentido del mundo y la capacidad de conceptuación de fenómenos y cosas para evidenciar nuestra percepción de lo existente, lo que genera la capacidad de creación y la virtualidad para ampliar nuestro horizonte intelectual, imaginativo, afectivo y espiritual (Rosario Candelier, 2010).

Segundo, desde la vertiente formal de la palabra, que funda la gracia de la expresión en su magnitud sensorial, sonora y elocuente. La belleza de la forma, centrada en la sensorialidad y la musicalidad de las palabras, es una vía adecuada para concitar la fascinación que la expresión encierra. Se trata del esplendor de la forma, que despierta el sentimiento y concita la expresión de la hermosura, que el lenguaje canaliza en el buen decir cuando el signo encauza el fulgor de lo viviente o huella prístina de lo divino. Esta faceta interior y trascendente comprende la dimensión estética y espiritual del lenguaje y la expresión de formas primorosas, cuando miramos adecuadamente: "Todo era hermoso en su tiempo" (Ec.3:11-13, Reyna Valera, 1960) pues al sentir la belleza del mundo, valoramos su bondad, su esplendor y su sentido. En tal virtud, descubrimos la verdad poética o lo que Luis Cernuda (2012, p.19) llamaba, en "El muchacho andaluz", una verdad de vida: "Eras tú una verdad, / sola verdad que busco, / más que verdad de amor, / verdad de vida". Además, la belleza también concita el sentimiento de la emoción estética, dimensión exclusiva del ser humano en virtud del don de creatividad que lo distingue y enaltece.

Y finalmente, la dimensión interior de la palabra, perspectiva que alude a la energía interior de la conciencia. El Logos de Heráclito, en cuya virtud se entiende la palabra como lenguaje y concepto, o el Logos de san Juan evangelista, que aludía a la Divinidad, finca la visión profunda de la palabra, así como el lenguaje del Protoidioma que comprende, según Fredo Arias de la Canal (Arias, 2008), la intuición de la belleza trascendente mediante el 
conocimiento de las imágenes arquetípicas. Esta concepción comprende la metafísica del lenguaje, predilecta de poetas, iluminados y contemplativos. Desde luego, implica también, como decía William Blake (2009) ser capaz de "ver un mundo en un grano de arena y al cielo en una flor silvestre", al tiempo que entraña la vertiente mística de lo viviente, cuando se asume el mundo como expresión de lo divino. En tal virtud, la palabra nos otorga un poder de convicción, de persuasión, de creación, de iluminación y, por supuesto, nos conecta con la sabiduría espiritual de la memoria cósmica. Y a ese objetivo ha de orientarse una buena docencia de la Lengua Española, ya que el aprendizaje de la forma correcta, del vocabulario preciso, de la forma elegante ha de motivar el cultivo del talento creador en nuestros estudiantes.

La palabra otorga un singular poder al hablante con conciencia de la lengua: un don para designar las cosas; un poder para conceptualizar el pensamiento; una certidumbre para edificar con la verdad nuestra conciencia; un vehículo para diseñar la visión del mundo; una dotación para proclamar nuestra valoración de las cosas y crear una nueva realidad verbal con belleza y sentido.

Desde los tiempos antiguos los estudiosos del lenguaje han consignado dos dimensiones esenciales relativas a la naturaleza de la palabra: el pensamiento y la expresión. La palabra es forma y contenido y, en tal virtud, hay una relación entre la palabra y la expresión, así como también entre el pensamiento y el lenguaje. Por esa razón, la palabra se carga de poder si la dotamos de nuestra convicción, de una prolífica pasión, de un espléndido ideal y de amor. Si hay conciliación entre la palabra y el concepto, se produce un lenguaje diáfano, coherente y preciso. De lo contrario, la expresión es deslucida, superficial y vacía. Si hay armonía entre la expresión y el contenido, podemos atestiguar con eficacia lo que advierte la sensibilidad y lo que intuye la inteligencia. Si hay adecuación entre el pensamiento y la palabra, discurre la conceptualización mediante la idea que intentamos transmitir.

El hablante común expresa en conceptos lo que quiere comunicar; en contraste, cuando el poeta escribe, enuncia lo que piensa mediante imágenes, que es el lenguaje que encauza la emoción de la belleza, propio del arte de la creación poética. Al pensar, los hablantes concretamos en conceptos lo que percibimos de las cosas; en consecuencia, podemos crear una verdad de hecho, basada en una realidad objetiva, que difiere de la verdad de juicio, inspirada en la estimación personal.

La verdad poética es fruto de una percepción intuitiva en nuestra comprensión de las cosas. Intuir (de intus 'dentro' y de ire 'entrar') es percibir el valor interior de cosas y fenómenos o la dimensión interna, metafísica o mística de lo existente. Lo que percibimos lo internalizamos en la conciencia. Hasta cierto punto, somos lo que pensamos y sentimos interiormente. Del conjunto de cuanto captamos o valoramos, creamos conciencia de las cosas con la estimación de hechos y fenómenos. Entonces adviene una conciencia intelectual, moral, estética y espiritual, que hemos de fomentar en nuestra docencia.

Mediante el don del lenguaje tenemos una singular capacidad para expresar nuestra percepción de las cosas, que enriquecemos con nuestra capacidad para embellecerlas y que potenciamos con nuestra capacidad de reflexión sobre su sentido o creando una nueva realidad con los recursos del lenguaje. La palabra está a nuestro servicio para crear belleza y generar sentido; para edificar, no para herir o injuriar; para expandir el horizonte cultural, no para descender; para canalizar lo que perciben la sensibilidad y la conciencia. 
La palabra tiene un significado, es decir, un concepto, un valor y un sentido. Son expresiones de la dimensión conceptual de los vocablos. Hay verdades profundas percibidas por la inteligencia intuitiva. Son nuestras verdades de vida o verdades derivadas de una experiencia vivencial o metafísica. Hay verdades trascendentes, reveladas por una voz superior. Son verdades universales, con valor en cualquier lengua y cultura. Se trata de la sabiduría espiritual del Universo, a la que acceden los grandes poetas cuyo torrente imaginativo y espiritual revelan verdades profundas mediante imágenes y símbolos arquetípicos.

Poetas, iluminados y contemplativos suelen ser intermediarios, como amanuenses del Espíritu o de la Voz alta del Cosmos, de verdades trascendentes. Los antiguos griegos hablaban de las musas como fuente de inspiración, concepto emparentado con el pneuma o soplo del Espíritu para los hebreos y el inconsciente colectivo de la psicología moderna de Carl Jung.(1970). Musa, pneuma o inconsciente colectivo aluden a lo que los cristianos identificamos como la señal del Espíritu Santo. La frase bíblica lo sintetiza mejor: "El Espíritu sopla donde quiere". Desde luego, para proyectar el sentido la palabra ha de reflejar la relación del contenido con el referente. Entre la palabra y el concepto hay una relación de adecuación, ya que entre la palabra y el referente que la inspira hay un vínculo de representación.

Por esa razón la enseñanza de la Lengua no puede cifrarse solo en exposición de principios, reglas y teorías, sino que se debe enmarcar en ejemplos de la Lengua viva, con modelos de creación en el arte del ensayo, la poesía y la ficción.

Entre la palabra y la experiencia vivencial hay una sintonía afectiva, imaginativa y conceptual. Una genuina poesía se apoya en verdades intuidas, no en especulaciones o suposiciones imaginativas. Entre la palabra y la idea que la conforma hay una sintonía conceptual fundada en la adecuación con la realidad de la cosa.

Si la palabra no se corresponde con la realidad que representa o con la huella que lo real imprime en la conciencia, se producen actitudes contradictorias. Si se hace una defensa teórica de los sujetos carentes de lo necesario para vivir, ha de implicar la generación de una actitud consecuente con lo que se predica, para que no sea una mera pose intelectual.

El drama de América Latina radica en que muchos de sus intelectuales y políticos ostentan una dualidad conceptual, ya que expresan una propuesta retórica sin la correspondencia operativa. Si entre lo que decimos y hacemos no hay adecuación, la palabra es falsa o mera retórica.

En virtud de la relación entre la palabra y el concepto, la capacidad de conceptualización conlleva la disposición para comprender el significado que las cosas entrañan. Hay una relación entre la palabra y el sentido que la palabra denota: procurar el sentido es entender la dimensión profunda de las cosas. Esa percepción permite identificar el bien o la bondad que encierra $y$, en tal virtud, es un importante aspecto a enfocar en la enseñanza de la lengua.

\section{El sentido en la enseñanza de la lengua}

La palabra tiene un sentido básico, que es el significado primario; un sentido metafórico, que es su dimensión traslaticia; y un sentido simbólico, que es su vertiente connotativa. La realidad sugiere también una valoración metafórica y una connotación metafísica. 
Cuando ambos aspectos se concilian, se produce una expresión coincidente entre la lengua y la realidad que la expresión estética del lenguaje canaliza en la faceta simbólica y trascendente de la expresión, y que una didáctica de la Lengua debe ponderar para abrir la comprensión en la inteligencia de los educandos.

Sabemos que, además de la verdad objetiva, hay una verdad subjetiva en función de la verdad de hecho y la verdad de juicio, respectivamente. Por esa razón hemos de aprender a respetar o al menos tolerar la verdad ajena, aunque estemos en desacuerdo. Eso es lo que enseña el ideal democrático de la cultura.

Pues bien, entre el hablante, la palabra, la belleza y el sentido hay una relación empática en virtud de la conexión que establece el sujeto contemplador con la cosa contemplada, y la expresión que revela esa relación. La creación artística en general, y literaria en particular, suele ser el producto estético de ese vínculo entrañable entre los ya mencionados factores de la comunicación.

Ante el impacto que lo real imprime en la sensibilidad y la conciencia, el contemplador registra la fascinación que la hermosura concita en la persona cuando entra en comunión con la cosa: entonces fluye no solo una relación armónica entre el sujeto y la cosa, sino la expresión hermosa y elocuente del sentimiento estético y espiritual, con la frase luminosa que encandila, la verdad profunda que ilumina o la belleza sutil que embriaga la conciencia. En tal virtud, entre la dimensión formal y conceptual de la palabra y ante la realidad de la cosa que la inspira, hay una relación de coparticipación y entrega, que el lenguaje formaliza en la expresión como se aprecia en las obras literarias, pictóricas y musicales. Esa fecunda relación entre la palabra y la cosa es lo que debe enfatizar el profesor de letras, si quiere hacer de la enseñanza una fuente de ilumi- nación, de conciencia plena y de inspiración de la creatividad.

Mediante la intuición el contemplador percibe la esencia y el sentido, cuando desde su sensibilidad profunda entra en el interior de la cosa y vive lo contemplado (Bergson, 1956). Entonces el enunciado de su lenguaje o el sentido de expresión portan un contenido revelador, edificante y sugerente. Entre la palabra, el contenido y la belleza, hay una empatía entrañable y sugerente. El contemplador experimenta esa singular vinculación cuando se abre a los fluidos de las cosas mediante la mirada interior, si es una mirada amorosa que atrapa el valor y el encanto de lo real. Entonces el contemplador percibe el bien que el ser contiene, con el sentido de su aliento inherente o la hermosura de su dimensión sensible.

Entre la palabra y el hablante hay un vínculo de posesión y de compenetración. Cuando el hablante se deja seducir por la esencia de la cosa o por la hermosura de su forma, se convierte en canal de sensaciones infinitas, en crisol de verdades intuidas o en amanuense de verdades reveladas. La verdad intuida es la que descubrimos cuando observamos la dimensión profunda de realidad material; la verdad revelada es la que nos llega de la memoria cósmica o de la sabiduría espiritual del Universo cuando sus efluvios trascendentes traspasan las compuertas de nuestra sensibilidad interior. La existencia de esas verdades y de las manifestaciones de la realidad sensible y suprasensible da lugar a que distingamos entre la voz personal y la voz universal: la primera entraña el testimonio de lo que perciben nuestros sentidos; la segunda contiene el torrente de conocimientos revelados por una fuerza misteriosa y profunda.

La realidad que nos apela y la reacción afectiva o imaginativa del contemplador, convoca una relación y una implicación psicológica. La persona acordada con su interior vive en 
armonía con lo que piensa, siente y hace. Esa armonía interior no solo refleja el sosiego de la conciencia, sino la apertura de la sensibilidad con sentido altruista y creador. Por eso, si entre lo que pensamos y sentimos no hay correspondencia, la palabra es falsa. Si entre lo que pensamos y decimos no hay adecuación, la palabra es hipócrita. Si entre lo que sentimos y hacemos no hay conformidad, nuestra palabra es fingida, a menos que se trate de una ficción, que la obra literaria consiente. Cuando acontece el divorcio entre la palabra, el pensamiento y la expresión, no hay verdad vivida, ni belleza sentida, ni emoción creíble. En esa condición tampoco fluye la intuición y, mucho menos, la creatividad. Ese desacuerdo explica las contradicciones conceptuales, morales, estéticas y espirituales, de tal manera que, si decimos que creemos en un más allá, pero experimentamos el sentimiento de horror al vacío, el miedo a la muerte desmiente esa creencia; si decimos que sentimos inclinación por la mística, nuestras acciones deben cortejar ese postulado espiritual. Porque si nuestra palabra o nuestra obra contradicen lo que decimos no tiene impacto lo que enseñamos.

De ahí que si la palabra es una adecuación entre forma y contenido, la virtualidad operativa del lenguaje debe reflejar ambas vertientes con claridad, propiedad y autenticidad. Esa adecuación es inexorable ya que entre la palabra y el sentido se dan varias concatenaciones consecuentes. Cuando advienen las incongruencias derivadas de las relaciones implicadas en el uso del lenguaje, la conducta y la creación reflejan la incoherencia en que incurren quienes despotrican contra la esencia de la cultura occidental por su procedencia europea o quienes adversan la institución cuyos beneficios usufructúan y ostentan.

Si aplicamos estos planteamientos a la docencia de la creación literaria, podemos inferir que una enseñanza sin esa compenetración intelectual, afectiva y espiritual, sin la convicción de la conciencia o la vibración de la sensibili- dad, lo mismo del pensamiento edificante o del amor transformante, es mera forma retórica sin trascendencia ni efectividad.

El propósito del buen escritor es crear una obra que cale la conciencia y la sensibilidad del lector por su sentido y su belleza. Desde luego, si podemos encauzar lo que el corazón anhela, podremos plasmar lo que la sensibilidad privilegia. Para formalizar la belleza de la forma y la hondura del concepto hemos de elegir la palabra con trascendencia de sentido y belleza en la expresión.

El poema de Bartolomé Lloréns, "Canción del agua viva" (Lloréns, 1993), inspirado en el "Cántico espiritual" de san Juan de la Cruz, ilustra el sentido de la belleza sutil con el concepto en la relación sensorial, afectiva, imaginativa, intelectual y espiritual que se produce entre la conciencia del hablante y la realidad material, vínculo que fragua la emoción estética y la fruición espiritual a la luz del sentido místico del mundo:

Mi amor se desnudaba a la orilla del agua, a la orilla de cielo, junto a la fuente clara. ¡La fuente de agua viva, secreta en la montaña!

Mi amor se desnudaba, a la orilla del agua.

Dejó las limpias prendas

Sobre las verdes ramas, y deshojó las flores que tejiera en guirnaldas. Se olvidó de los pájaros que en la umbría cantaban, del rumor de las frondas, del beso de las auras. Y en su puro desnudo Se contempló en las aguas.

En su desnudo puro junto a la fuente clara. 
Su imagen intangible de luminosa gracia, vio esfumarse, fundirse, entre la viva plata, de aquella eterna fuente secreta en la montaña.

\section{Mi amor se reflejaba en las ondas de plata.}

Dejó mi amor la orilla y se perdió en las aguas. En su eterna corriente, murmura, fluye, canta, onda entre vivas ondas, luz entre luces altas. ¡Cielo mismo en el cielo, que las aguas arrastran!

Dejó mi amor la orilla y en la corriente canta.

¡Oh fuente de agua viva, que en lo escondido mana! No volvió a la ribera, que su amor era el agua.

\section{Referencias}

Arias, F. (2008). Diálogos intemporales, p. 37. México: Frente de Afirmación Hispanista.
Blake, W. (2009). Ver al mundo en un grano de arena. Madrid: Visor.

Bergson, H. (1956). Introducción a la metafísica, p.16. Buenos Aires: Leviatán.

Cernuda, L. (2012). Antología Poética. p.19. Sevilla: Espasa.

Jung, C. (1970). Arquetipos e inconciente colectivo, pp.9-24. Barcelona: Paidos Ibérica.

Llorens, B. (1993). Antología poética, pp. 29-30. Edición de José Julio Cabanillas. Sevilla: España.

Platón (s.f.). Diálogos de Platón, p. 164. Obras Maestras: Iberia.

Plutarco (s.f.). [Los cerebros no son vasos que se han de llenar, sino antorchas que se han de encender]. Recuperado de URL: https://franciscojaviertostado. com/2014/09/12/una-deuda-conplutarco/

Rosario Candelier, B. (2010). El Logos en la conciencia, p. 7. Santo Domingo, Academia Dominicana de la Lengua.

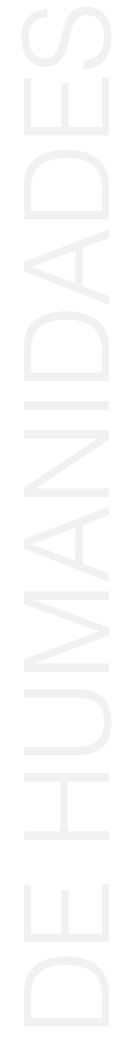

